\title{
Investigation of the Potential Serum Levels of Autophagy 5-protein, Apo-Lipoprotein B-48, and Oxidative Stress Markers in the Early Diagnosis of Patients with Ischemic Stroke
}

\section{Amir Ajoolabady}

Tabriz Medical University: Tabriz University of Medical Sciences

\section{Fatma Sogutlu}

Ege University Faculty of Medicine: Ege Universitesi Tip Fakultesi

Masoud Nikanfar

Tabriz Medical University: Tabriz University of Medical Sciences

Alireza Nourazarian ( $\square$ alinour65@gmail.com )

Tabriz University of Medical Sciences https://orcid.org/0000-0003-2082-1335

Delara Laghousi

Tabriz University: University of Tabriz

behrouz shademan

Ege University Faculty of Medicine: Ege Universitesi Tip Fakultesi

\section{Research Article}

Keywords: Apo-lipoprotein B-48, Autophagy 5-protein, Ischemic stroke, Oxidative stress

Posted Date: October 25th, 2021

DOI: https://doi.org/10.21203/rs.3.rs-1001373/v1

License: (c) (i) This work is licensed under a Creative Commons Attribution 4.0 International License.

Read Full License 


\section{Abstract}

Background: Stroke is one of the leading causes of death worldwide and has different characteristics. Different physiopathological mechanisms characterize the different subtypes of ischemic stroke. In this study, we investigated the correlation between serum levels of autophagy-5 protein, Apo-lipoprotein B-48, and oxidative stress markers in patients with ischemic stroke.

Methods and results: We enrolled 100 participants, including 50 ischemic stroke (IS) patients as the case group and 50 healthy individuals as the control group. Then, we conducted a case-control study at Imam Reza Hospital from March 2019 to April 2020. We quantified the serum levels of ATG5, Apo B-48, and oxidative stress markers in both groups. And we evaluated the incremental diagnostic value of these factors by receiver operating characteristic analysis (ROC) in both groups. The mean serum levels of ATG5, Apo B-48, and oxidative stress markers were higher in the case group than in the control group, with a $p$-value of less than $0.0001(p<0.0001)$.

Conclusions: Serum levels of ATG5, Apo B-48, Malonaldehyde (MDA), total oxidative stress (TOS), and total antioxidant capacity (TAC) in patients with IS can be used as novel biomarkers to predict or therapeutically modulate patients with IS.

\section{Introduction}

Stroke is one of the most common diseases leading to death in developed countries. Stroke affects approximately 15 million people worldwide, one-third of whom die and the remainder suffers from the disease permanently [1]. Stroke is a multifaceted disease with different subtypes with well-defined physiopathological mechanisms [2]. Although numerous therapeutic approaches, including lifestyle and dietary modification and pharmaceutical interventions, are used to treat IS, the prevalence of ischemic stroke is still high, especially in developed countries [3]. Due to the formation of blood clots in the vessels, blood flow can no longer reach the brain, resulting in a lack of oxygen and nutrients and ultimately damaging brain tissue [4]. Predicting the consequences of IS is imperative to both clinicians and patients [5]. To date, prognostic strategies used by clinicians have not correctly predicted the consequences of IS in patients [6]. Therefore, using blood markers associated with pathological features of IS such as cardiovascular disease, inflammation, and neuronal damage provides prognostic clinical models [7]. Current research suggests that autophagy is stimulated in various cerebrovascular diseases such as IS. However, the underlying mechanisms of autophagy regulation in ischemia remain largely unknown [810].

Elevated serum levels of Apo B are associated with IS and intracranial atherosclerotic disease [11]. Oxidative stress plays a central role in cerebral I/R damage. According to IS, oxidative stress mediates necrosis and apoptosis through various mechanisms. Strategies to reduce ROS (reactive oxygen species) may help mitigate IS-induced brain damage [12]. Therefore, it is reasonable to conduct a study to investigate the correlation between these agents in patients with IS. The current study was conducted to 
analyze the correlation between serum levels of ATG5, Apo B-48, and oxidative stress markers in patients with IS.

\section{Materials And Methods Study population}

We conducted a case-control study in Imam Reza Hospital from March 2019 to April 2020. We enrolled 100 participants, including 50 patients with IS ( 22 women and 28 men) as the case group and 50 healthy individuals without ischemic stroke or another neurological disease (23 women and 27 men) as the control group. Magnetic resonance imaging (MRI) and computed tomography (CT) were used for radiological diagnosis of the patients with IS. Inclusion criteria consisted of a diagnosis of IS and completion of a form. Exclusion criteria included IS history, infarcts, epilepsy, circulatory disorders, postnatal disease, ischemic cardiovascular disease (CVD), pregnancy, hypothyroidism, renal disease, cerebral sinus thrombosis, brain tumors, contraceptives, and pharmaceutical preparations affect the results and a history of migraine. Infarct size was also assessed with a threshold of $2.0 \mathrm{~cm}$.

\section{Blood sample collection}

After fasting for 12 hours, 10 -ml blood samples were collected by phlebotomy. The samples could then clot at room temperature for 1-2 hours. After clotting, the samples were centrifuged at $1200 \mathrm{~g}$ for 10 minutes. Then the collected serum samples were transferred to other vials and stored at $70^{\circ} \mathrm{C}$ for later analysis. Serum levels of ATG5, Apo B-48, and oxidative stress markers such as malondialdehyde (MDA), TOS, and TAC were measured. Cholesterol kits (cat. no. $110500 \mathrm{BT}$ ), triglyceride kits (GPO-PAP, cat. no. 132504 H917), and HDL kits (cat. no. 1050012), all from Pars Azmoon, Iran, were used to evaluate the lipid profile with the Hitachi 917 . We used the Friedewald formula for the quantification of low-density lipoprotein (LDL) [13].

\section{Measuring the serum levels of ATG5, Apo B-48, and oxidative stress markers}

For the measurement of ATG5, Apo B-48, and oxidative stress markers, Elisa kits from Elabscience Biotechnology Inc. (Cat. No. E-BC-K143, China), (Cat. No. E-EL-H0149, China) and My BioSource (Cat. No. MBS 037744, USA) was used.

\section{Statistical analysis}

For data analysis, Graph Pad Prism 8, Mann-Whitney U test, and logistic regression were used. Additionally, the Kolmogorov-Smirnov test was used to assess the normality of quantitative variables, and percent frequency and mean \pm SD were used to obtain qualitative and quantitative variables, respectively. ROC curves were used to determine the most appropriate table stop values to distinguish between healthy participants and patients with IS. A Spearman test was performed to evaluate the 
correlation between ATG5, Apo B-48, and oxidative stress markers in both groups. A p 0.05 was considered a significant difference in both groups.

\section{Results}

\section{Demographic data of the subject}

The study included 50 samples from the case group and 50 samples from the control group. As Table 1 shows, there were no significant differences in diabetes, smoking, age, sex, alcohol consumption, weight, and height between the two groups ( $p>0.05)$. However, there were notable differences in hypertension and Body mass index (BMI) between the two groups ( $p<0.05$ ). And $54 \%$ of patients with IS (27 patients) had large vessel ischemic stroke, while $46 \%$ of patients with IS (23 patients) had small vessel ischemic stroke.

\section{Table 1}

Demographic characteristics of the study population. 


\begin{tabular}{|c|c|c|c|c|}
\hline Variable & Total & Control & Case & P-value \\
\hline N (\%) Gender & & & & 0.50 \\
\hline Female & 45 & $23(51.1 \%)$ & $22(49 \%)$ & \\
\hline Male & 55 & $27(49.1 \%)$ & $28(51 \%)$ & \\
\hline Age, Mean (SD) & & $54.16(14.2)$ & $58.46(10.5)$ & 0.89 \\
\hline \multicolumn{5}{|l|}{ History of Cigarette, N (\%) } \\
\hline Yes & 26 & $11(42.3 \%)$ & $15(57.7 \%)$ & 0.247 \\
\hline No & 74 & $39(52.7 \%)$ & $35(47.3 \%)$ & \\
\hline History of Alcohol, N (\%) & & & & 0.143 \\
\hline Yes & 17 & $6(35.3 \%)$ & $11(64.7 \%)$ & \\
\hline No & 83 & $44(53.0 \%)$ & $39(47.0 \%)$ & \\
\hline N (\%) History of Diabetic disease, & & $12(41.4 \%)$ & $17(58.6 \%)$ & 0.189 \\
\hline Yes & 29 & $38(53.5 \%)$ & $33(46.5 \%)$ & \\
\hline No & 71 & & & \\
\hline N (\%) History of Hypertension, & 42 & $15(35.7 \%)$ & 27 (64.3\%) & 0.013 \\
\hline Yes & 58 & $35(60.3 \%)$ & $23(39.7 \%)$ & \\
\hline \multicolumn{5}{|l|}{ No } \\
\hline Height, Mean (SD) & & $167.42(9.5)$ & $167.68(9.7)$ & 0.89 \\
\hline Weight, Mean (SD) & & $69.70(12.4)$ & $70.2(12.7)$ & 0.84 \\
\hline BMI, Mean (SD) & & $20.67(1.6)$ & $24.63(3.6)$ & $<0.001$ \\
\hline
\end{tabular}

\section{Evaluation of the serum levels of biochemical factors}

As Table 2 shows, there are significant differences in serum levels of ATG5, Apo B-48, TG, cholesterol, and oxidative stress markers such as MDA, TOS and TAC between both groups. However, no remarkable differences were found in serum levels of LDL-C and HDL-C between both groups.

Table 2

Comparison of the blood levels of the biochemical parameters between case and control groups 


\begin{tabular}{|llll|}
\hline Variable & $\begin{array}{l}\text { Control } \\
\text { Mean (SD) }\end{array}$ & $\begin{array}{l}\text { Patients with a stroke } \\
\text { Mean (SD) }\end{array}$ & P-value* \\
\hline Apo B48( $\mu \mathrm{g} / \mathrm{mL})$ & $4.09(0.35)$ & $4.67(0.26)$ & $<0.0001$ \\
\hline ATG5 $(\mathrm{ng} / \mathrm{mL})$ & $18.60(3.2)$ & $29.72(6.2)$ & $<0.0001$ \\
\hline MDA $(\mathrm{nmoL} / \mathrm{mL})$ & $1.60(0.30)$ & $1.97(0.46)$ & $<0.0001$ \\
\hline TOS $(\mu \mathrm{moL} / \mathrm{L})$ & $10.72(1.14)$ & $11.89(1.62)$ & $<0.0001$ \\
\hline TAC $(\mathrm{mmoL} / \mathrm{L})$ & $1.23(0.22)$ & $1.48(0.29)$ & $<0.0001$ \\
\hline LDL-C(mg/dL) & $105.92(37.5)$ & $112.90(49.0)$ & 0.426 \\
\hline HDL-C(mg/dL) & $46.26(9.4)$ & $44.62(10.8)$ & 0.422 \\
\hline CHOL $(\mathrm{mg} / \mathrm{dL})$ & $172.28(38.9)$ & $192.54(58.4)$ & $<0.044$ \\
\hline TG $(\mathrm{mg} / \mathrm{dL})$ & $152.64(57.1)$ & $200.38(64.4)$ & \\
\hline $\begin{array}{l}\text { T-test was used. } \\
\text { TG: } \text { Triglyceride, LDL-C: Low-density lipoprotein cholesterol, CHOL: Cholesterol, HDL-C: High-density } \\
\text { lipoprotein cholesterol }\end{array}$ & & \\
\hline
\end{tabular}

\section{Evaluation of ATG5, Apo B-48, MDA, TOS, and TAC Serum Levels}

As Figure 1 shows, serum levels of ATG5 were significantly increased $(29.72 \pm 6.2 \mathrm{ng} / \mathrm{ml})$ compared to the control group $(18.60 \pm 3.2 \mathrm{ng} / \mathrm{ml})$ with p 0.0001 . Serum levels of Apo B-48 were significantly increased in the case group $(4.67 \pm 0.26 \mu \mathrm{g} / \mathrm{ml})$ compared to the control group $(4.09 \pm 0.35 \mu \mathrm{g} / \mathrm{ml})$ with $\mathrm{p}$ 0.0001 . Serum levels of MDA were significantly increased in the case group $(1.97 \pm 0.46 \mathrm{nmol} / \mathrm{ml})$ compared to the control group $(1.60 \pm 0.30 \mathrm{nmol} / \mathrm{ml})$ with $p<0.0001$. Serum levels of TOS were significantly increased in the case group $(11.89 \pm 1.62 \mu \mathrm{mol} / \mathrm{I})$ compared to the control group $(10.72 \pm$ $1.14 \mu \mathrm{mol} / \mathrm{I})$ with $p<0.0001$. Serum TAC levels were significantly elevated in the case group $(1.48 \pm 0.29$ $\mathrm{mmol} / \mathrm{l})$ compared to the control group $(1.23 \pm 0.22 \mathrm{mmol} / \mathrm{l})$ with $\mathrm{p}<0.0001$.

\section{logistic regression analysis}

As shown in Table 3, logistic regression analysis revealed that with a one-unit increase in serum levels of Apo B-48, ATG5, MDA, TOS, and TAC, the odd of developing IS increased 905-, 2-, 15-, 1.8-, and 53-fold, respectively, which is statistically significant $(P<0.05)$.

Table 3 
The relationship between the blood levels of Apo B48, ATG5, and stress biomarkers and Stroke disease by Logistic regression

\begin{tabular}{|llllll|}
\hline Variables & B & S. E & Odds ratio & $95 \% \mathrm{Cl}$ & P-value $^{*}$ \\
\hline Apo B48 $(\mu \mathrm{g} / \mathrm{mL})$ & 6.808 & 1.328 & 905.375 & 67.016 to 12231.446 & $<0.0001$ \\
\hline ATG5 $(\mathrm{ng} / \mathrm{mL})$ & 0.712 & 0.156 & 2.039 & 1.501 to 2.769 & $<0.0001$ \\
\hline MDA $(\mathrm{nmoL} / \mathrm{mL})$ & 2.734 & 0.692 & 15.388 & 3.960 to 59.790 & $<0.0001$ \\
\hline TOS $(\mu \mathrm{moL} / \mathrm{L})$ & 0.600 & 0.167 & 1.822 & 1.314 to 2.527 & $<0.0001$ \\
\hline TAC $(\mathrm{mmoL} / \mathrm{L})$ & 3.985 & 1.002 & 53.792 & 7.547 to 383.402 & $<0.0001$ \\
\hline *Logistic regression was used. & & & \\
\hline
\end{tabular}

\section{Analyzing ROC curve}

To investigate the diagnostic value of the above serum factors, a ROC curve analysis is required. As shown in Table 4, the area under the ROC curve (AUC) values for ATG5, Apo B-48, MDA, TOS, and TAC were $0.9656,0.9120,0.7530,0.7102$, and 0.7588 of $95 \%$, respectively. The results were statistically significant at $p 0.05$ because the area under the curve of the results ( $95 \%$ confidence interval) did not have an AUC value of 0.5. The largest AUC belongs to ATG5 and Apo B-48, indicating these two parameters are more suitable for diagnosing IS (Figure 2). Table 5 shows the cutoff values for ATG5, Apo B-48, MDA, TOS, and TAC based on the Youden index results. According to the Youden index, the best cutoff value for Apo B-48 is a serum level of $\geq 4.35$, indicating that serum levels above 4.35 indicate patients with IS. Serum levels below 4.35 indicate healthy individuals. Additionally, the sensitivity is $84 \%$, and the specificity is $80 \%$ at this cutoff value, so $84 \%$ of patients with IS and $80 \%$ of healthy individuals is correctly diagnosed as patients with IS and healthy individuals, respectively. Also, the cutoff value of ATG5 in serum $\geq 23.5$ shows a sensitivity of $90 \%$ and a specificity of $96 \%$ in diagnosing patients with IS and healthy individuals, respectively (Table 5).

Table 4

The AUC analysis for Apo B48, ATG5, and stress biomarkers in IS patients. 


\begin{tabular}{|lllll|}
\hline Variable(s) & Area & Std. Error & $95 \% \mathrm{Cl}$ & P-Value \\
\hline Apo B48 $(\mu \mathrm{g} / \mathrm{ml})$ & 0.9120 & 0.02708 & 0.8589 to 0.9651 & $<0.0001$ \\
\hline ATG5 $(\mathrm{ng} / \mathrm{mL})$ & 0.9656 & 0.01607 & 0.9341 to 0.9971 & $<0.0001$ \\
MDA $(\mathrm{nmoL} / \mathrm{mL})$ & 0.7530 & 0.04821 & 0.6585 to 0.8475 & $<0.0001$ \\
& & & & \\
TOS $(\mu \mathrm{moL} / \mathrm{L})$ & 0.7102 & 0.05181 & 0.6086 to 0.8118 & 0.0003 \\
& & & & \\
TAC $(\mathrm{mmoL} / \mathrm{L})$ & 0.7588 & 0.04814 & 0.6644 to 0.8532 & $<0.0001$ \\
& & & & \\
\hline
\end{tabular}

Table 5

The sensitivity and specificity of the Apo B48, ATG5, and stress biomarkers in the detection of stroke according to the Youden index

\begin{tabular}{|llll|}
\hline Variable & Cutoff point value & sensitivity & specificity \\
\hline Apo B48 $(\mu \mathrm{g} / \mathrm{mL})$ & $\geq 4.35$ & 0.84 & 0.80 \\
\hline ATG5 $(\mathrm{ng} / \mathrm{mL})$ & $\geq 23.5$ & 0.90 & 0.96 \\
\hline $\mathrm{MDA}(\mathrm{nmoL} / \mathrm{mL})$ & $\geq 1.85$ & 0.62 & 0.76 \\
\hline $\operatorname{TOS}(\mu \mathrm{moL} / \mathrm{L})$ & $\geq 10.32$ & 0.84 & 0.42 \\
\hline $\operatorname{TAC}(\mathrm{mmoL} / \mathrm{L})$ & $\geq 1.235$ & 0.80 & 0.48 \\
\hline
\end{tabular}

\section{Spearman's correlation}

The results of the Spearman correlation test showed there was a small but statistically nonsignificant association between serum levels of ATG5, Apo B-48, MDA, TOS, and TAC in patients with IS ( $p>0.05)$ (Table 6).

Table 6 
The correlation between serum concentration of the Apo B48, ATG5, and stress biomarkers in the detection of stroke

\begin{tabular}{|llll|}
\hline Variable & N & Correlation coefficient & P-value $^{*}$ \\
\hline Apo B48 $(\mu \mathrm{g} / \mathrm{mL})$ & 50 & -0.070 & 0.629 \\
\hline ATG5 $(\mathrm{ng} / \mathrm{mL})$ & 50 & 0.081 & 0.576 \\
\hline $\operatorname{MDA}(\mathrm{nmol} / \mathrm{mL})$ & 50 & -0.203 & 0.158 \\
\hline $\operatorname{TOS}(\mu \mathrm{mol} / \mathrm{L})$ & 50 & 0.045 & 0.757 \\
\hline $\operatorname{TAC}(\mathrm{mmol} / \mathrm{L})$ & 50 & 0.032 & 0.828 \\
\hline
\end{tabular}

\section{Logistic regression analysis}

An analysis of the correlation between serum levels of Apo B-48, ATG5, MDA, TOS, and TAC with vascular involvement in patients with IS by logistic regression analysis revealed there was no statistically significant correlation between the serum levels of these factors and vascular involvement in IS patients $(P>0.05)$ (Table 7).

Table 7

The relationship between the blood levels of Apo B48, ATG5, and stress biomarkers and type of vessel involvement ${ }^{*}$ in patients with stroke disease.

\begin{tabular}{|lccccc|}
\hline Variable & B & S. E & Odds ratio & $95 \% \mathrm{Cl}$ & P-value $^{*}$ \\
\hline Apo B48 $(\mu \mathrm{g} / \mathrm{mL})$ & 1.395 & 1.116 & 4.033 & 0.452 to 35.958 & 0.212 \\
\hline ATG5 $(\mathrm{ng} / \mathrm{mL})$ & 0.092 & 0.052 & 1.096 & 0.991 to 1.213 & 0.075 \\
\hline MDA $(\mathrm{nmoL} / \mathrm{mL})$ & -1.295 & 0.739 & 0.274 & 0.064 to 1.166 & 0.080 \\
\hline TOS $(\mu \mathrm{moL} / \mathrm{L})$ & -0.138 & 0.178 & 0.871 & 0.614 to 1.235 & 0.438 \\
\hline TAC $(\mathrm{mmoL} / \mathrm{L})$ & -0.119 & 0.959 & 0.888 & 0.135 to 5.820 & 0.901 \\
\hline * Logistic regression was used. & * type of vessel involvement: Large vessel and small vessel. \\
\hline
\end{tabular}

\section{Discussion}


Current research suggests that autophagy is stimulated in various cerebrovascular diseases, such as IS. However, the underlying mechanisms of autophagy regulation in ischemia and IS are still largely unknown. In rats with middle cerebral artery occlusion (MCAO) (IS), microRNA-9a-5p (miR-9a-5p) was downregulated, which contributed to neurological deficits via induction of excessive autophagy after MCAO. However, overexpression of miR-9a-5p led to downregulation of ATG5 levels and attenuation of autophagy $[8,14]$. This study suggests that miR-9a-5p regulates the expression of ATG5 and inhibits hyperactivation of autophagy, leading to the alleviation of neurological deficits in ischemic stroke.

Similarly, downregulation of miR-30b contributed to excessive autophagy induction by promoting ATG12ATG5 conjugates, further enhancing liver injury under hepatic ischemia [15]. This study also demonstrates that the involvement of ATG5 in excessive autophagy is damaging to human tissues under ischemia. ATG5 supported mitochondrial function and promoted angiogenesis in endothelial cells under pathological hypoxia/reoxygenation (H/R) [16]. Therefore, endothelial ATG5 represents a novel therapeutic opportunity for abnormalities related to neovascularization. Up-regulation of STAT3 (Signal Transducer and Activator of Transcription 3) resulted in ATG5-mediated autophagy, which attenuated liver injury after hepatic I/R in vitro and in vivo [17]. Thus, mild induction of autophagy under ischemic conditions alleviates human tissue damage.

The effect of lipoprotein abnormalities on the onset or progression of cerebrovascular ischemia remains unclear. The mendelian Randomization Study (MR) comparatively examined the effects of apolipoproteins and lipids at IS. The study found that $A p o B$ is of paramount importance and contributes to the formation of triglycerides, LDL cholesterol, and Apo B associated with IS [18]. Besides exploring the potential role of the Apo E polymorphism in ischemic cerebrovascular abnormalities, the 4 alleles may predispose to ischemic cerebrovascular disease [19]. Additionally, increased serum levels of Apo $B$ and an increased Apo B/apoA1 ratio correlate with IS and intracranial atherosclerotic disease. However, no difference was found between serum levels of Apo B and Apo A1 in IS subtypes [11]. But further studies are needed to further explain the relationship between serum apolipoproteins and IS. Oxidative stress is a significant factor involved in cerebral I/R damage. Oxidative stress directly contributes to apoptosis and necrosis through multiple mechanisms. Therefore, by applying strategies to block the formation of oxidative stress, IS-induced neural damage can be attenuated $[12,20]$. And Narne and coworkers have extensively studied the effects of oxidative stress, epigenetic changes, and mitochondrial energy metabolism on IS pathology [21].

Overall, many studies have been conducted to describe the relationship between autophagy, apolipoproteins, and oxidative stress in IS pathophysiology. But few studies have analyzed the correlation between these elements in IS. There is a need for studies describing how ATG proteins, apolipoproteins, and oxidative stress markers correlate with patients with IS. In this context, we selected ATG5, Apo B-48, and oxidative stress markers and analyzed the correlation between serum levels of these factors in patients with IS.

\section{Conclusion}


Overall, serum levels of ATG5, Apo B-48, MDA, TOS, and TAC are higher in patients with IS than in healthy subjects. Additionally, the current study indicates a small but statistically nonsignificant association between serum levels of ATG5, Apo B-48, MDA, TOS, TAC, and BMI in the case group. Given the small size of the study population, we suggest that further large-scale studies be conducted to validate the results. We suggest that serum levels of ATG5, Apo B-48, MDA, TOS, and TAC in ischemic stroke patients can be used as novel biomarkers to predict or therapeutically modulate patients with IS. We suggest that serum levels of ATG5, Apo B-48, MDA, TOS, and TAC in patients with IS can be used as novel biomarkers to predict or therapeutically modulate patients with ischemic stroke.

\section{Declarations}

\section{Acknowledgments}

We appreciate the kind helps of the Neurosciences Research Center of Tabriz University of Medical Sciences.

\section{Author contributions}

AN, BS and MN were involved in study design; DL and FS contributed to analysis and interpretation of data; $A A, M N$ contributed to revising the manuscript content. AN gave consent for the final version of the manuscript.

\section{Funding}

This study was supported by a grant from Tabriz University of Medical Sciences (IR.TBZMED.REC.1399.879).

\section{Data availability}

The data and materials used in this study are available.

\section{Conflict of interest}

The authors declare there are no conflicts of interest.

\section{Ethical approval}

The Ethics Committee of the Tabriz University of medical sciences approved the study protocols following the Declaration of Helsinki. 


\section{Consent to publication}

All authors agree to publish the data of this study.

\section{References}

1. Meschia JF, Brott T (2018) Ischaemic stroke. Eur J Neurol 25(1):35-40. https://doi.org/10.1111/ene.13409

2. Chen R, Ovbiagele B, Feng W (2016) Diabetes and stroke: epidemiology, pathophysiology, pharmaceuticals and outcomes. Am J Med Sci 351(4):380-386. https://doi.org/10.1016/j.amjms.2016.01.011

3. Katan M, Luft A (2018) Global burden of stroke. In Seminars in neurology (Vol. 38, No. 02, pp. 208211). Thieme Medical Publishers. https://doi.org/10.1055/s-0038-1649503

4. Jin Q, Li R, Hu N, Xin T, Zhu P, Hu S, ... Zhou H (2018) DUSP1 alleviates cardiac ischemia/reperfusion injury by suppressing the Mff-required mitochondrial fission and Bnip3-related mitophagy via the JNK pathways. Redox Biol 14:576-587. https://doi.org/10.1016/j.redox.2017.11.004

5. Arslan AK, Colak C, Sarihan ME (2016) Different medical data mining approaches based prediction of ischemic stroke. Comput Methods Programs Biomed 130:87-92

6. Jampathong N, Laopaiboon M, Rattanakanokchai S, Pattanittum P (2018) Prognostic models for complete recovery in ischemic stroke: a systematic review and meta-analysis. BMC neurol 18(1):111. https://doi.org/10.1186/s12883-018-1032-5

7. Chehaibi K, Trabelsi I, Mahdouani K, Slimane MN (2016) Correlation of oxidative stress parameters and inflammatory markers in ischemic stroke patients. J Stroke Cerebrovasc Dis 25(11):2585-2593

8. Wang N, Yang L, Zhang H, Lu X, Wang J, Cao Y, ... Wang L (2018) MicroRNA-9a-5p alleviates ischemia injury after focal cerebral ischemia of the rat by targeting ATG5-mediated autophagy. Cell Physiol Biochem 45(1):78-87. https://doi.org/10.1159/000486224

9. Ajoolabady A, Aghanejad A, Bi Y, Zhang Y, Aslkhodapasandhukmabad H, Abhari A, Ren J (2020) Enzyme-based autophagy in anti-neoplastic management: from molecular mechanisms to clinical therapeutics. Biochim Biophys Acta Rev Cancer 1874(1):188366. https://doi.org/10.1016/j.bbcan.2020.188366

10. Ren J, Sun M, Zhou H, Ajoolabady A, Zhou Y, Tao J, ... Zhang Y (2020) FUNDC1 interacts with FBXL2 to govern mitochondrial integrity and cardiac function through an IP3R3-dependent manner in obesity. Sci Adv 6(38):eabc8561

11. Shademan B, Nourazarian A, Laghousi D, Karamad V, Nikanfar M (2021) Exploring potential serum levels of Homocysteine, interleukin-1 beta, and apolipoprotein B 48 as new biomarkers for patients with ischemic stroke. J Clin Lab Anal, e23996. https://doi.org/10.1002/jcla.23996

12. Manzanero S, Santro T, Arumugam TV (2013) Neuronal oxidative stress in acute ischemic stroke: sources and contribution to cell injury. Neurochem Int 62(5):712-718 
13. Mehri H, Aslanabadi N, Nourazarian A, Shademan B, khaki-khatibi F (2021) Evaluation of the serum levels of Mannose binding lectin-2, tenascin-C, and total antioxidant capacity in patients with coronary artery disease. J Clin Lab Anal, e23967. https://doi.org/10.1002/jcla.23967

14. Ajoolabady A, Aslkhodapasandhokmabad H, Aghanejad A, Zhang Y, Ren J (2020) Mitophagy receptors and mediators: therapeutic targets in the management of cardiovascular ageing. Ageing Res Rev, 101129. https://doi.org/10.1016/j.arr.2020.101129

15. Li SP, He JD, Wang Z, Yu Y, Fu SY, Zhang HM, ... Shen ZY (2016) miR-30b inhibits autophagy to alleviate hepatic ischemia-reperfusion injury via decreasing the Atg12-Atg5 conjugate. World $\mathrm{J}$ Gastroenterol 22(18):4501

16. Sprott D, Poitz DM, Korovina I, Ziogas A, Phieler J, Chatzigeorgiou A, ... Klotzsche-von Ameln A (2019) Endothelial-specific deficiency of ATG5 (autophagy protein 5) attenuates ischemia-related angiogenesis. Arterioscler Thromb Vasc Biol 39(6):1137-1148. https://doi.org/10.1161/ATVBAHA.119.309973

17. Han YF, Zhao YB, Li J, Li L, Li YG, Li SP, Li ZD (2018) Stat3-Atg5 signal axis inducing autophagy to alleviate hepatic ischemia-reperfusion injury. J Cell Biochem 119(4):3440-3450. https://doi.org/10.1002/jcb.26516

18. Yuan S, Tang B, Zheng J, Larsson SC (2020) Circulating lipoprotein lipids, apolipoproteins and ischemic stroke. Ann Neurol 88(6):1229-1236. https://doi.org/10.1002/ana.25916. Epub 2020 Oct 10

19. Pedro-Botet J, Senti M, Nogues X, Rubiés-Prat J, Roquer J, D'Olhaberriague L, Olivé J (1992) Lipoprotein and apolipoprotein profile in men with ischemic stroke. Role of lipoprotein (a), triglyceride-rich lipoproteins, and apolipoprotein E polymorphism. Stroke 23(11):1556-1562. https://doi.org/10.1161/01.STR.23.11.1556

20. Ajoolabady A, Wang S, Kroemer G, Klionsky DJ, Uversky VN, Sowers JR, ... Ren J (2021) ER stress in cardiometabolic diseases: from molecular mechanisms to therapeutics. Endocr Rev. https://doi.org/10.1210/endrev/bnab006

21. Narne P, Pandey V, Phanithi PB (2017) Interplay between mitochondrial metabolism and oxidative stress in ischemic stroke: an epigenetic connection. Mol Cell Neurosci 82:176-194. https://doi.org/10.1016/j.mcn.2017.05.008

\section{Figures}


A

B
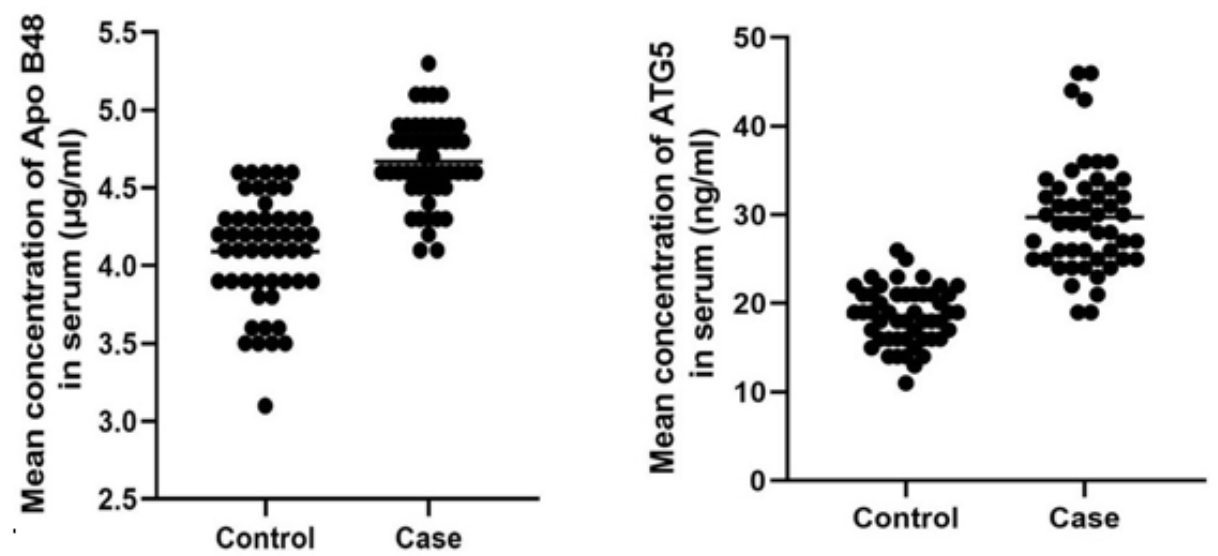

C

D
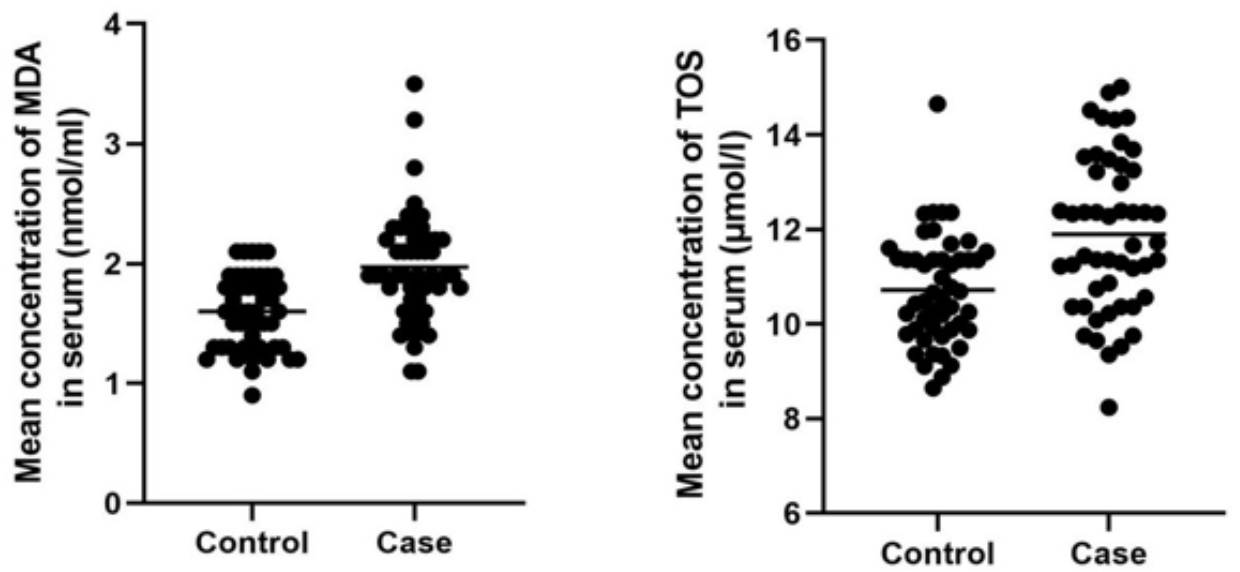

E

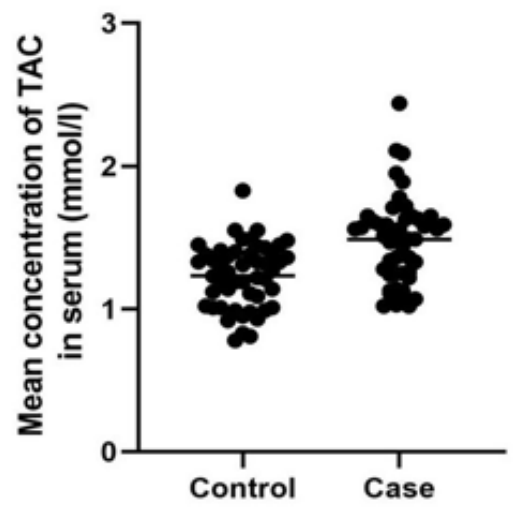

Figure 1

Mean concentration of the Apo B48(A), ATG5(B), MDA(C), TOS(D) and TAC(E) in IS patients and the control group. 
A

B
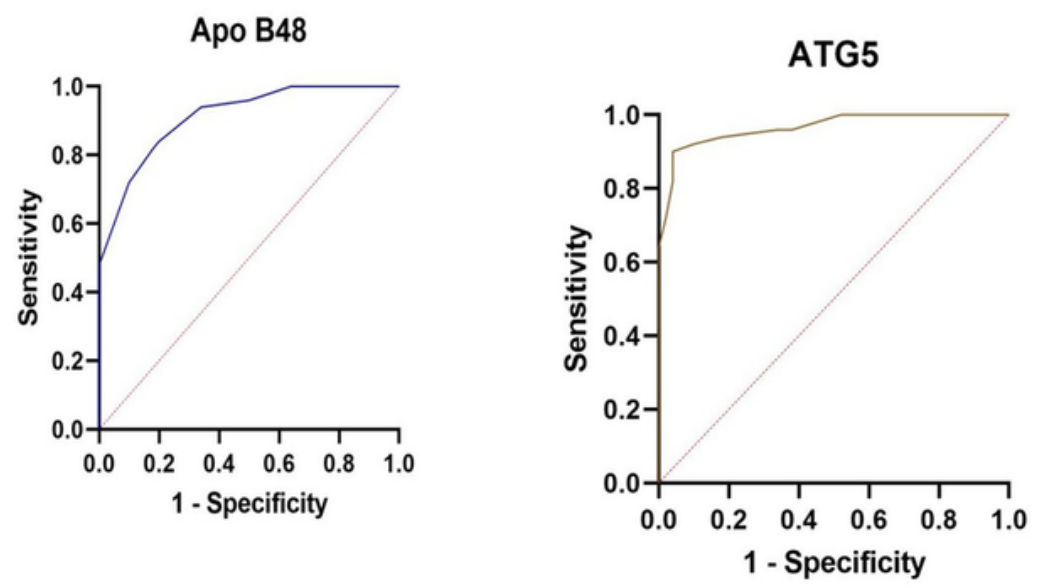

C

D

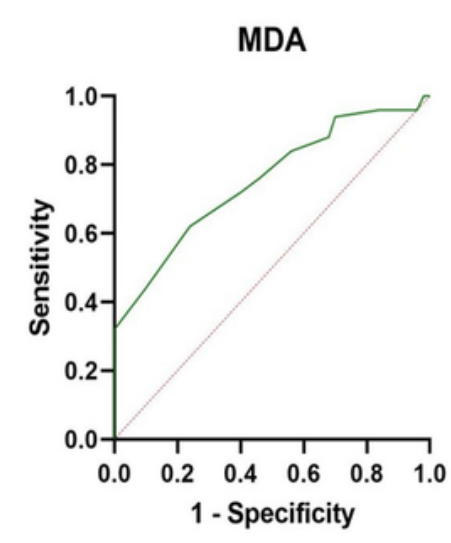

TOS

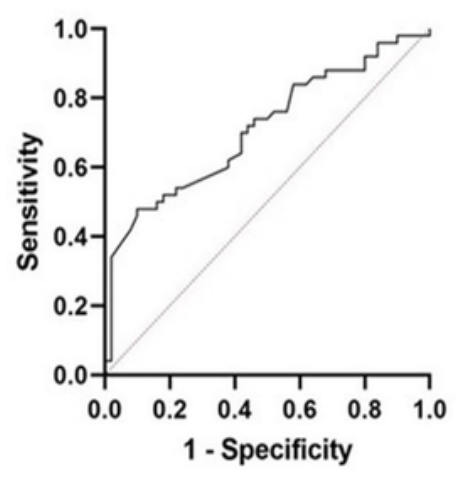

E
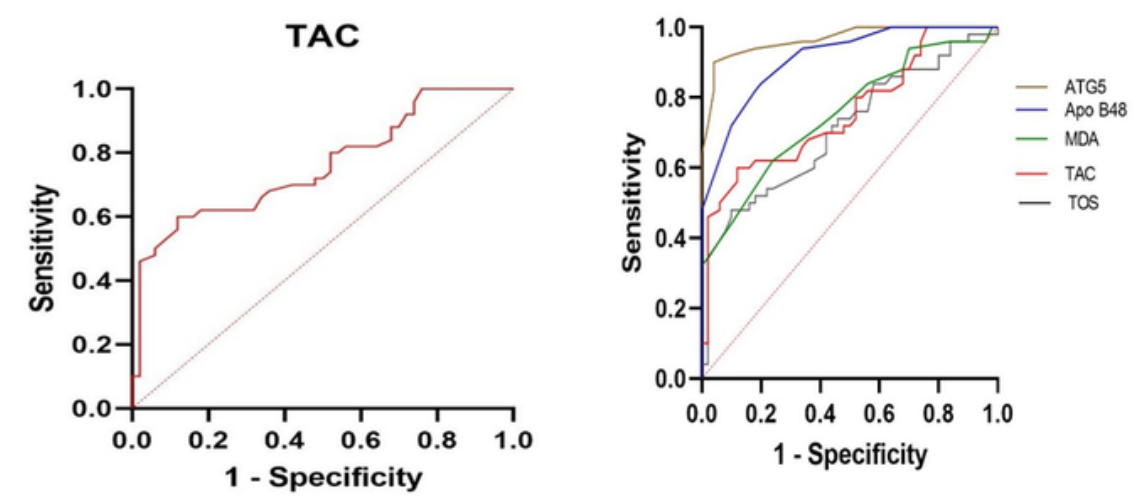

\section{Figure 2}

ROC curves analysis for serum concentrations of Apo B48(A), ATG5(B), MDA(C), TOS(D) and TAC(E) in patients with a Stroke. 